\title{
AS QUATRO ESTAGões DE SEI SHôNAGON
}

\author{
Luiza Nana Yoshida
}

Na segunda metade do século $\mathrm{X}$ e no início do século $\mathrm{XI}$, não podemos deixar de destacar o importante papel desempenhado pela mulher, dentro da Literatura Clássica Japonesa, principalmente desde que a escrita deixou de ser privilégio só dos homens, e foi difundida entre as mulheres da aristocracia, depois do século IX ${ }^{(1)}$.

Podemos citar como algumas das principais obras da época e as suas respectivas autoras:

- Kagerô nikki (século X) - Michitsuna no haha

- Makura no sôshi (século XI) - Sei Shônagon

- Murasaki Shikibu nikki (século XI) - Murasaki Shikibu

- Genji monogatari (século XI) - Murasaki Shikibu

- Sarashina nikki (século XI) - Sugawara no Takasue no musume

que ora refletem as divagacooes das suas autoras, ora se tornam registros de suas queixas e lamentações.

Excetuando-se Genji monogatari, um dos maiores romances clássicos japoneses, essas obras são, na maioria, em formas de ensaios ou diários, escritos pelas mulheres pertencentes à aristocracia da época.

Makura no sòshi, considerada uma das obras primas dentro da literatura de ensaio, resultou da perspicaz capacidade de observação e da aguda sensibilidade de Sei Shônagon.

Sei Shônagon cujo pai e avô (Kiyohara no Motosuke e Kiyohara no Fukayabu, respectivamente) foram poetas de renome, provavelmente passou a escrever Makura no sôshi durante a sua permanência no palácio imperial, quando servia à imperatriz Teishi como dama da corte.

Makura no sôshi compõe-se de aproximadamente trezentos ensaios, cujo conteúdo pode ser separado, de modo geral, em três grupos a saber:

1 - Ensaios com temas semelhantes - onde a autora, através da sua perspicaz observação e ponto de vista, faz definiçōes, prin-

(1) Até o aparecimento do silabário kana, típicamente japonês, o povo japonês utilizava-se do kanbun, escrita chinesa. O silabário kana, além de ser mais acessivel, por ser menos complexo do que o kanbun, abriu caminho aos japoneses de melhor se expressarem utilizando a sua própria escrita. 
cipalmente no que se refere à natureza, à vida e à sensibilidade do homem.

2 - O cotidiano do palácio imperial (tipo diário e memórias) onde a autora registra facetas da vida da imperatriz, a sua própria vivência no Palácio e alguns fatos do dia a dia palaciano.

3 - Ensaios propriamente ditos - onde a autora escreve sobre as impressões do momento, e se nota a sua sensibilidade estética à procura do belo no que refere à natureza e ao homem.

No grupo 1 iremos encontrar dois tipos de introdução em japonês: wa, como Toriwa. (Quanto ao pássaro ), Yamawa (Quanto à montanha. ), Mushiwa (Quanto ao inseto ) etc., onde a autora traz na cabeça da história o sujeito em questão sobre o qual ela irá emitir suas opiniões.

b) mono, como susamajikimono (Aquilo que é desagradável), arigatakimono (Aquilo que é raro) etc., onde a autora enumera uma série de coisas ou fatos que considera ser, ora desagradável, ora raro etc.

O ensaio que abre Makura no sôshi é uma das mais conhecidas dentro da Literatura Clássica Japonesa, sendo que a sua frase inicial Haruwa akebono tornou-se tão famosa nos meios literários modernos que ela, por si só, equivale a um sinônimo da própria obra Makura no sôshi.

O nosso modesto trabalho sobre Makura no sôshi versará exatamente sobre esse ensaio.

\section{A primavera é o amanhecer}

Quanto à primavera, o seu instante mais belo é o amanhecer. A linha do horizonte por sobre a montanha vai, pouco a pouco, se esbranquiçando, se tornando clara e as nuvens, em tom lilás, formam faixas horizontais por todo o céu.

Quanto ao verão, a sua hora mais agradável é a noite. Se há lua, a noite é perfeita; mas mesmo as noites em que a lua se esconde se torna agradável, quando vaga-lumes mil cintilam na escuridão. Até mesmo a chuva é bem-vinda nas noites de verão.

Quanto ao outono, o seu melhor momento é o entardecer. Quando o sol poente tinge o céu de púrpura e vai se escondendo por detrás da montanha, até a figura dos corvos retornando para os seus ninhos em grupos de três, quatro ou dois, nos tocam o coração. Assim, torna-se ainda mais interessante avistar-se ao longe os gansos selvagens 
voarem enfileirados. Ouvir o som do vento e o trinar dos insetos depois da chegada já da noite..

Quanto ao inverno, o melhor é de manhãzinha. Se houver neve, não há mais o que desejar. Quando o dia amanhece todo branco por causa da geada, ou mesmo que não haja neve ou geada, mas a manhã esteja bastante fria, as mulheres atravessam os corredores da casa ${ }^{(2)}$, levando carvões acescs, depois de feito o fogo às pressas ${ }^{(3)}$. É uma cena que se ajusta perfeitamente a uma manhã de inverno.

Quando o sol se levanta e o frio tende a se atenuar pouco a pouco, o fato de tanto o carvão do irori (4), quanto o do braseiro se transformar em cinza parece quebrar toda a harmonia da ocasião.

Aqui a autora fala sobre as quatro estaçōes do ano, enfocando o horário que melhor expressa cada uma delas.

Nós que vivemos num país onde o ano inteiro parece se resumir em apenas duas estações, verão e inverno, não conseguimos sentir, de início, o quão feliz foi Sei Shônagon na escolha do melhor momento de cada estação. Para isso, temos de levar em conta que o Japão é um dos países em que existe a nítida definição das quatro estações, e, talvez, por isso mesmo, as pessoas sejam extremamente ligadas à natureza e se sensibilizem particularmente com as várias mudanças que ocorrem a cada estação.

Com o seu estilo preciso, Sei Shônagon oferece-nos em cada descrição uma imagem simples, destituída de adornos, mas de rara beleza, que mostra a natureza no seu esplendor e nos seus melholes momentos. Para isso a autora não se limitou a acatar os valores estéticos da época, mas mos'rou possuir uma sensibilidade estética peculiar, como quando considera o amanhecer como o instante mais belo da primavera, enquanto nos poemas da época cantava-se o dia ou a noite da primavera como o seu momento supremo.

\section{Quanto à primavera, o seu momento mais belo é o amanhecer}

As noites suaves e os dias enfeitados com as flores da cerejeira são, sem dúvida, imagens muito belas na primavera. $O$ amanhecer, porém, citado por Sei Shônagon parece-nos ser o seu momento mais belo. Isto porque o amanhecer é o descortinar de um novo dia, assim como a primavera é ,por assim dizer, o "amanhecer" das quatro estações, quando o céu vai, pouco a pouco, se clareando para depois se colorir num tom primaveril.

(2) As construções arquitetonicas da época possuíam, em geral, corredores externos que ligavam praticamente todos os aposentos.

(3) Os carvões acesos faziam o papel, digamos, dos fósforos de hoje. Distribuía-se, então, os carvões nos vários cômodos onde houvesse irori (vide nota 4) ou braseiro para se aquecer o ambiente.

(4) Irori - uma espécie de lareira cavada no assoalho. Servia também como um fogareiro, quando se desejava esquentar ou cozinhar alguma coisa. 
A autora utiliza a palavra akebono para indicar o amanhecer. Esta é uma palavra que possui conotação temporal. No japonês clássico, existem várias palavras para indicar o amanhecer em seus vários estágios, mas, de uma maneira geral, poderiamos indicar esses estágios ordenando-as da seguinte maneira: sendo que,

akatsuki $\rightarrow$ shinonome $\rightarrow$ akebono $\rightarrow$ tsutomete

- akatsuki - é o início do amanhecer, quando o céu se encontra ainda escuro;

- shinonome - é o instante em que os raios do sol começam a despontar;

- akebono - é o momento em que o céu começa a se abrir e a claridade, a aumentar;

- tsutomete - é o amanecer propriamente dito, quando o processo se completa.

Akebono é, portarto, o exato momento em que o céu começa a se clarear lentamente. $E$ o céu que faz limite com a montanha vai aumentando a sua claridade, enquanto nuvens pairam como adornos em tom lilás. É uma cena mais do que própria para representar toda a beleza da primavera.

\section{Quanto ao verão, a sua hora mais agradável é a noite}

No verão japonês, quente e úmido, nada melhor do que a chegada da noite para se desfrutar o frescor noturno. O verão é a estação em que a vida parece mais agradável e aproveitável à noite, que se caracteriza por ser mais curta nesta estação. Assim a presença da lua clareando o céu, torna-se desejável, não só por isso, mas também pelo fato de as pessoas disporem, na época, de precários instrumentos de iluminação.

Mesmo quando a lua não surge, a noite torna-se agradável, quando se avistam vaga-lumes cintilando e colorindo a escuridão da noite. Até mesmo a chuva que normalmente é indesejada, torna-se bem-vinda como um elemento amenizador do calor e como um adorno de fios prateados.

Podemos perceber que todos os elementos levantados: noite, lua, vaga-lume cintilando na escuridão, chuva têm em comum o fato de possuirem algo que, de um modo ou outro, causam a sensação de frescor.

\section{Quanto do outono, o seu melhor momento é to entardecer}

O céu do outono caracteriza-se pela sua limpidez. Talvez por esse fato o seu pôr-do-sol seja tão especial. E a figura do corvo que normalmente possui uma conotação negativa, casa-se perfeitamente com essa paisagem outonal, quando, em grupos, voam de volta para os seus ninhos, que chega a comover quem a vê. Mais comovente então 
é contemplar os gansos selvagens que se alinham como pontilhados no céu. Na Literatura Clássica Japonesa o ganso selvagem era constantemente citado como símbolo da melancolia, devido à sua condição de ave migratória.

O som do vento e a sinfonia dos insetos típicos do outono, famosos pelos seus trinados noturnos, depois do pôr-do-sol, completam o cuadro que retrata o outono no seu melhor momento.

\section{Quanto ao inverno, o melhor é de manhãzinha}

Isto porque o inverno sendo a estação do frio, é pela manhã que esse frio é sentido mais rigorosamente, e é o instante em que o homem se sente mais próximo do inverno.

Quando pela manhã tudo se encontra coberto de neve, sente-se estar num outro mundo. A neve como parte integrante dessa estação traz a harmonia nessas manhãs de inverno.

Também quando sobrevem uma geada, ou numa manhã simplesmente muito fria, as pessoas acendem apressadamente os carvões, passam pelos corredores da casa levando os carvóes já acesos para aquecer os aposentos. É uma cena que também se casa perfeitamente com as manhãs do inverno, causando uma sensação de harmonia e equilíbrio.

Quando, pelo contrário, com o avançar do dia o frio se ameniza e os carvões dos irori e dos braseiros vão se tornando cinzas, isso parece desequilibrar o ambiente, quebrando toda a harmonia existente.

Como pudemos ver, a autora foi capaz de sintetizar de uma maneira muito objetiva mas abrangente, as quatro estações do ano, mostrando as suas principais caracteristicas e retratando, o que é mais importante, um quadro belissimo de cada uma delas. Para isso, Sei Shônagon procurou apelar para os vários sentidos do ser humano:

— primavera $\rightarrow$ esbranquiçando clara lilás (cores - visão)

— verão $\rightarrow$ lua escuridão vaga-lume (claro/escuro - visão)

- outono $\rightarrow$ corvos gansos selvagens (visão) $\rightarrow$ som do vento trinar dos insetos (audição)

- inverno $\rightarrow$ neve geada (frio - tato)

Resumindo o quadro de cada estação teríamos:

- primavera $=$ amanhecer

Sendo a estação predominantemente de um colorido especial, principalmente pela presença das flores, foi retratada através de um visual colorido: esbranquiçando clara lilás

- verão $=$ noite

O verão é retratado no seu melhor momento através do jogo de luzes claro-escuro: lua escuridão vaga-lume que denotam, de 
certo modo, o frescor necessário para os dias quentes e também pela presença da chuva, um elemento atenuador do calor sufocante.

- outono $=$ entardecer

Através da utilização de animais que realçam a beleza do entardecer outonal, do som do vento e o trinar dos insetos a autora nos sugere um outono que se caracteriza por uma tranquilidade e calma, apesar do movimento (corvos e gansos selvagens) e do som, assim como quando adormecemos ouvindo o som calmo de uma chuva.

- inverno $=$ manhãzinha

$O$ inverno ẽ a estação que mais diretamente age sobre o nosso sentido do tato, através do seu frio cortante. Para enfatizar essa característica, encontramos a neve e a geada que são uma espécie de concretização do inverno, pois podemos nelas tocar e sentir na pele o frio característico dessa estação.

Assim são definidas as quatro estações por Sei Shônagon. A sensação que nos fica, após a leitura de Haruwa akebono, é a de que a autora foi capaz de pintar, em rápidas mas precisas pinceladas, um quadro que retrata o que há de mais belo ou interessante em cada uma das estações, manifestando assim a sua perspicaz capacidade de observação e a sua grande sensibilidade com relação à natureza.

\section{BIBLIOGRAFLA}

ICHIKO, Teiji - Kobun. Tóquio, Galkken, 1983.

IKEDA, Kikan - Zenkô Makura no sôshi. Tóquio, Shibundô, 1967.

KIMURA, Massanaka - Makura no soshi Sakuhin kansho, in: Nihon no koten 6. Tóquio, Shaeisha, 1979.

MARUYAMA, Kazuhika - Koten kobun. Tóquio, Bun'eidô, 1980.

MATSUO, Satoshi e NAGAI, Kazuko - Makura no sôshi. Toquilo Shogakkan, 1974.

TANAKA, Jataro - Makura no sôshi zenchashaku 1. Tóquio, Kadokawa, 1972. 